\title{
STUDY ON GLAUCOMA AWARENESS AMONG PATIENTS ATTENDING A TERTIARY HEALTH CENTRE
}

\section{Ophthalmology \\ Dr Atul Kumar Anand}

Dr Sachin Kumar*
Assistant Professor, Department of Ophthalmology, NMCH, Patna.

Assistant

\section{Dr Rajesh Kumar} Tiwary

Professor \& Head, Department of Ophthalmology, NMCH, Patna.

\section{ABSTRACT}

Globally, glaucoma is a leading cause of irreversible blindness. In India approx. 11.2 million People aged above 40 years are affected with glaucoma. Studies shows that the prevalence of this disease increases with age \& more than $90 \%$ are unaware of it. Lack of awareness about glaucoma is an important reason for its late presentation which significantly increases the risk of blindness. A Hospital based cross sectional study was conducted in the ophthalmology department of NMCH, Patna. Total 1860 patients of age group 20-80 years coming to OPD were enrolled for the study. The study was conducted by using a pre structured questionnaires. The questions were in English \& local language (Hindi). Each question had 3 options and patient had to choose one. Source of information about glaucoma was also enquired. Data were collected through face to face interviews. In our study overall awareness on glaucoma was $16.02 \%$. Male patients were comparatively more aware than females. Similarly urban \& semi-urban residents were more aware than rural population. As the age and education increased level of awareness \& knowledge increased. Major source of information was from doctors, health personnel \& mass media. A large number of participants had heard about the local term used for glaucoma i.e. kalamotia but few were actually aware about it and very few were aware of the fact that in glaucoma, the raised intraocular pressure damage the nerve resulting in blindness. Progression of glaucoma can only prevented by early diagnosis and treatment. So, awareness about the glaucoma will help in early detection, a very important step in preventing glaucoma related blindness. We can decrease the prevalence of glaucoma by spreading awareness and screening of risk group population.

\section{KEYWORDS}

\section{Glaucoma, Awareness, Blindness}

\section{INTRODUCTION}

Glaucoma is described as silent killer of the vision, because in majority of the cases it remains asymptomatic for a long period. The progression of this disease is very slow and patient aware of it in very late stage. Globally, glaucoma is a leading cause of irreversible blindness ${ }^{1}$. In India approx. 11.2 million people aged above 40 years are affected with glaucoma. Out of this 6.48 million are diagnosed to have primary open angle glaucoma as reported in George et al study ${ }^{2}$. Studies shows that the prevalence of this disease increases with age \& more than $90 \%$ are unaware of it

In a study in Andhra Pradesh the prevalence rate of POAG in more than 30 years age was $1.62 \%$ in urban population while other studies reported the prevalence of glaucoma in India to be 2.6 to $4.1 \%{ }^{4}$. Krishnaiah et $\mathrm{al}^{5}$ reported the lack of awareness on glaucoma among the rural population of India. Lack of awareness about glaucoma is an important reason for its late presentation ${ }^{6,78}$ which significantly increases the risk of blindness ${ }^{9}$

Rewri P et al ${ }^{10}$ study showed that education \& awareness can prevent glaucoma related blindness.

\section{AIMS OF THE STUDY}

The purpose of the study is to evaluate the awareness \& knowledge about glaucoma among the patients coming to the OPD of ophthalmology department of NMCH, Patna.

\section{MATERIAL \& METHODS}

A Hospital based cross sectional study was conducted in the ophthalmology department of Nalanda Medical College \& Hospital, Patna. Total 1860 patients of age group 20-80 years coming to OPD were enrolled for the study. General details like name, age, sex, literacy $\&$ residential address were noted. Prior written informed consent was taken from every patient for the study.

The study was conducted by using a pre structured questionnaires. The questions were in English \& local language (Hindi). The questionnaire began with the entry level question - Have you heard of glaucoma (kalamotia in Hindi)? If the response to this question was 'Yes' the participants were allowed to take up the rest of questions, evaluating awareness and knowledge about glaucoma (4 Questions about awareness \& 6 questions for assessing their knowledge). Each question had 3 options and patient had to choose one.
Having only heard about the term glaucoma was not considered as awareness, because merely being aware of the term do not ensure awareness about the disease. However, not having heard the term itself means lack of awareness.

Source of information about glaucoma was also inquired. Data were collected through face to face interviews.

\section{INCLUSION CRITERIA}

All patients of age group 20-80 years coming to the OPD of ophthalmology department of NMCH, Patna.

\section{EXCLUSION CRITERIA}

1. Patients of less than 20 years \& above 80 years of age

2. Patients of subnormal mental status

\section{RESULTS}

A total 1860 patients participated in this cross sectional study. Out of which $986(53.01 \%)$ were males while $874(46.99 \%)$ were females.

Out of 1860 patients only $298(16.02 \%)$ were aware of glaucoma in which 164 were males \& 134 were females.

\section{TABLE 1}

\begin{tabular}{|l|l|l|l|}
\hline Gender & Aware & Not aware & Total \\
\hline Male & $164(16.63 \%)$ & $822(83.37 \%)$ & $986(100 \%)$ \\
\hline Female & $134(15.33 \%)$ & $740(84.67 \%)$ & $874(100 \%)$ \\
\hline Total & 298 & 1562 & 1860 \\
\hline
\end{tabular}

In relation to the age, maximum awareness i.e. 114 patients were of age group 20-40 years followed by 41-60 years of age group (102 patients). Minimum awareness (82 patients) was found in the age group 61-80 years (Figure 1)

\section{FIGURE 1}

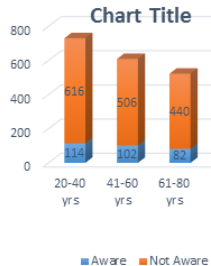


With respect to the residence minimum awareness was found in rural population (48 patients) while maximum (142) in urban patients followed by semi-urban patients ( 108 cases).

TABLE 2

\begin{tabular}{|l|l|l|l|}
\hline Residence & Aware & Not Aware & Total \\
\hline Urban & $142(27.10 \%)$ & $382(72.90 \%)$ & $524(100 \%)$ \\
\hline Semi-Urban & $108(20.53 \%)$ & $418(79.47 \%)$ & $526(100 \%)$ \\
\hline Rural & $48(5.93 \%)$ & $762(94.07 \%)$ & $810(100 \%)$ \\
\hline Total & 298 & 1562 & 1860 \\
\hline
\end{tabular}

In relation to the literacy, maximum awareness was found in graduates \& postgraduates (137 patients) followed by intermediates \& diplomas (101 patients) while least awareness ( 60 cases) in below $10^{\text {th }}$ standards.

\section{TABLE 3}

\begin{tabular}{|l|l|l|l|}
\hline Education & Aware & Not Aware & Total \\
\hline Upto $10^{\text {th }}$ std. & $60(7.87 \%)$ & $702(92.13 \%)$ & $762(100 \%)$ \\
\hline+2 d diplomas & $101(17.75 \%)$ & $468(82.25 \%)$ & $569(100 \%)$ \\
\hline Graduates \& PGs & $137(25.90 \%)$ & $392(74.10 \%)$ & $529(100 \%)$ \\
\hline Total & 298 & 1562 & 1860 \\
\hline
\end{tabular}

Regarding source of information, $33.22 \%$ got information from doctors \& health personnel, $30.20 \%$ patients from mass media (TV/ radio/ newspaper). In $29.87 \%$ patients source of information was family \& friends and in $6.75 \%$ from social media (Figure 2 ).

\section{FIGURE 2}

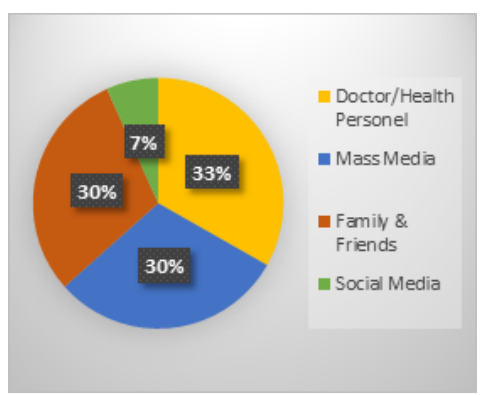

\section{DISCUSSION}

This study tells about the awareness \& knowledge regarding glaucoma among the patients coming to the hospital.

In our study overall awareness on glaucoma was $16.02 \%$. As per Nirmala et al $^{11}$ study $18.23 \%$ awareness on glaucoma was found. Male patients were comparatively more aware than females. Similarly urban $\&$ semi-urban residents were more aware than rural population.

In present study awareness $\&$ knowledge was better among individuals with higher education. Graduates \& PGs had good knowledge. Similar trends were reported by other awareness prevalence studies ${ }^{6,12}$.

Patients of age group 20-60 years had more awareness \& knowledge about glaucoma. As the age and education increased, level of awareness \& knowledge also increased. So, age and literacy played the major role in awareness on glaucoma.

Major source of information was from doctors, health personnel \& mass media.

A large number of participants had heard about the local term used for glaucoma i.e. kalamotia but few were actually aware about it and very few were aware of the fact that in glaucoma, the raised intraocular pressure damage the nerve resulting in blindness.

The limitation of the study is that interviewer's bias could not be completely eliminated as on individual's expression, language and style of explanation may affect the response of the participants ${ }^{10}$. Since it is a Hospital based study, it may not give clear picture of awareness in the society.

\section{CONCLUSION}

This study enlightens us that awareness \& actual knowledge about glaucoma in patients coming to the hospital is poor. As we know that glaucoma is a disease of few or no symptoms in early stage. Progression of glaucoma can only prevented by early diagnosis and treatment. So, awareness about the glaucoma will help in early detection, a very important step in preventing glaucoma related blindness.

Therefore, we can decrease the prevalence of glaucoma by spreading awareness and screening of risk group population. We can use mass media \& social media to educate the people about glaucoma.

\section{REFERENCES}

1. Resnikoff S, Pascolini D, Etya'ale D, Kocur I, Pararajasegaram R, Pokharel GP, et al. Global data on visual impairment in the year 2002. Bull World Health Organ. 2004:82:844-51. [PMC free article] [PubMed] [Google Scholar]

2. George R, Ve RS, Vijaya L. Glaucoma in India: estimated burden of disease. J Glaucoma. 2010 Aug;19(6):391-7. doi: 10.1097/IJG.0b013e3181c4ac5b. [PubMed].

3. Vijaya L, George R, Baskaran M, Arvind H, Raju P, Ramesh SV, et al. Prevalence of primary open-angle glaucoma in an urban South Indian population and comparison with a rural population .The Chennai glaucoma study. Ophthalmology. 2008;115:648-54. [PubMed].

4. Jacob A, Thomas R, Koshi SP, Braganza A, Muliyil J. Prevalence of primary glaucom in an urban south Indian population. Indian J Ophthalmol. 1998 Jun;46(2):81-6. [PubMed.

5. Krishnaiah S, Kovai V, Srinivas M, Shamanna BR, Rao GN, Thomas R. Awareness of glaucoma in the rural population of Southern India. Indian J Ophthalmol. 2005 Sep;53(3):205-8. [PubMed]

6. Attebo K, Mitchell P, Cumming R, Smith W. Knowledge and beliefs about common eye diseases. Aust N Z J Ophthalmol. 1997;25:283-7. [PubMed] [Google Scholar].

7. Fraser $\mathrm{S}$, Bunce $\mathrm{C}$, Wormald R. Risk factors for late presentation in chronic glaucoma Invest Ophthalmol Vis Sci. 1999;40:2251-7. [PubMed] [Google Scholar]

8. Gogate P, Deshpande R, Chelerkar V, Deshpande S, Deshpande M. Is glaucom blindness a disease of deprivation and ignorance? A case-control study for late blindness a disease of deprivation and ignorance? A case-control study for late
presentation of glaucoma in India. Indian J Ophthalmol. 2011 Jan-Feb;59(1):29-35. presentation

9. Javitt JC. Preventing blindness in Americans: The need for eye health education. Surv Ophthalmol. 1995;40:41-4. [PubMed] [Google Scholar].

10. Rewri P, Kakkar M. Awareness, knowledge, and practice: a survey of glaucoma in north Indian rural residents. Indian J Ophthalmol. 2014 Apr;62(4):482-6. doi: 10.4103/03014738.132105. [PubMed].

11. Nirmala, Antharjanam D, Krishnan G, Harsha C.H, Mary Ann, Londhe S, Antony R. Study on glaucoma awareness among the rural population of central Kerala.Int J Med Res Rev 2016;4(9):1582-1586.doi:10.17511/ijmrr. 2016.i09.11.

12. Dandona R, Dandona L, John RK, McCarty CA, Rao GN. Awareness of eye diseases in an urban population in Southern India. Bull World Health Organ. 2001;79:96-102. [PMC free article] [PubMed] [Google Scholar] 